\title{
Broken Ribs: Paleopathological Analysis of Costal Fractures in the Human Identified Skeletal Collection From the Museu Bocage, Lisbon, Portugal (Late 19th to Middle 20th Centuries)
}

\author{
Vítor Matos* \\ Centro de Investigação em Antropologia e Saúde, Department of Anthropology, University of Coimbra, \\ Coimbra 3000-056, Portugal \\ KEY WORDS paleopathology; forensic anthropology; thoracic injuries; tuberculosis; pneumonia
}

\begin{abstract}
Although rarely reported in the anthropological literature, rib fractures are commonly found during the analysis of human skeletal remains of past and modern populations. This lack of published data precludes comparison between studies and restricts an accurate understanding either of the mechanisms involved in thoracic injuries or their impact on past societies. The present study aimed: 1) to report rib fracture prevalence in 197 individuals, 109 males, and 88 females, with ages at death ranging from 13 to 88 years old, from the Human Identified Skeletal Collection, Museu Bocage, Portugal (late 19th-middle 20th centuries); 2) to test the hypothesis that a higher prevalence of rib stress fractures existed in the 133 individuals who died from respiratory diseases, in a period before antibiotics. The macroscopic analysis revealed $23.9 \%(n=47)$ of individuals
\end{abstract}

Rib fractures are reported as a common finding in the analysis of human skeletal remains of both past and modern populations (Lovell, 1997; Aufderheide and Rodríguez-Martín, 1998; Jurmain, 1999; Campillo, 2001; Ortner, 2003; Roberts and Cox, 2003; Roberts and Manchester, 2005; Brickley, 2006; Rodríguez-Martín, 2006). Nevertheless, their quantification and detailed description are rarely "consistently reported" (Jurmain, 1999: 226-7) either in the paleopathological or forensic anthropology literature. Exceptions are, for example, the study by Brickley (2006) on archeological material and the analysis of rib fractures from forensic contexts such as those performed by Marmor (1969) and by Love and Symes (2004). This scarcity of published data on rib fractures precludes comparisons between studies and restricts an accurate understanding and reconstruction of violent or nonviolent injuries inflicted to the thorax. This scenario is not surprising since biocultural approaches to the study of fractures in past human populations have classically emphasized cranial and long bones (Grauer and Roberts, 1996; for a revision see Lovell, 1997). However, the interest in ribs as a valuable and important source of paleopathological information has grown in the last few years, a phenomenon probably related to the following: 1) the significant improvement concerning the excavation techniques of archaeological skeletal material (Roberts and Manchester, 2005) has resulted in a more efficient and careful recovery of ribs, minimizing their fragmentation; 2) methodological tools were developed with the purpose of rib identification, with broken ribs. 2.6\% ( $n=124)$ out of 4,726 ribs observed were affected. Males presented more rib fractures, and a significantly higher prevalence was noted for older individuals. Fractures were more frequently unilateral $(n=34)$, left sided $(n=19)$ and mainly located on the shaft of ribs from the middle thoracic wall. Nineteen individuals presented adjacent fractured ribs. Individuals who died from pulmonary diseases were not preferentially affected. However, a higher mean rate of fractures was found in those who died from pneumonia, a scenario still common nowadays. Since rib involvement in chest wall injury and its related outcomes are important issues both for paleopathology and forensic anthropology, further investigations are warranted. Am J Phys Anthropol 140:25-38, 2009. @ 2009 Wiley-Liss, Inc.

namely their sequencing and siding (Dudar, 1993; Mann, 1993; Hoppa and Saunders, 1998; Owers and Pastor, 2005); 3) more investigations dedicated to these bones have been published in the last two decades, such as those concerning the rib morphology and biomechanics (Usher and Christensen, 2000; Fily et al., 2001; Franciscus and Churchill, 2002; Groves et al., 2003; Streeter and Stout, 2003; Cho et al., 2006), or the role of rib lesions in assisting in the differential diagnosis of pulmonary diseases (Kelley and Micozzi, 1984; Molto, 1990; Pfeiffer, 1991; Wakely et al., 1991; Roberts et al., 1994, 1998; Santos, 2000; Santos and Roberts, 2001; Lambert, 2002; Mays et al., 2002; Byers and Roberts, 2003; Matos, 2003; Matos and Santos, 2006; Raff et al., 2006; Santos and Roberts, 2006).

\footnotetext{
Grant sponsor: Fundação para a Ciência e Tecnologia; Grant number: SFRH/BD/16155/2004.

*Correspondence to: Vítor Matos, Departamento de Antropologia, Universidade de Coimbra, Coimbra 3000-056, Portugal.

E-mail: vmatos@antrop.uc.pt
}

Received 15 March 2008; accepted 3 December 2008

DOI 10.1002/ajpa.21032

Published online 17 March 2009 in Wiley InterScience (www.interscience.wiley.com). 
However, further work is still needed regarding rib analysis from both past and modern populations. Regarding rib fractures in past societies, as Brickley (2006, p 64) suggests, more "detailed level of recording" is necessary in order to maximize the data recovered. The study performed by Brickley (2006) on the individuals unearthed from the St. Martin's Church, Birmingham (18-19th centuries), is the first paleopathological approach with an in depth analysis devoted exclusively to rib fractures. The remaining works reporting rib fractures from archaeological material (Robledo and Trancho, 1999; Assis, 2007; Curate, 2007; Garcia, 2007; Jordana, 2007) confine their studies to the overall prevalence of rib fractures, some of these including sex and age distributions, but lack a fine grained analysis concerning the patterns of rib involvement and consequences of these to the individuals afflicted. Thus, more investigation is necessary on this topic to achieve a better picture of the changing patterns of both violent and nonviolent injuries inflicted to the thorax over time, and whether these reflect transformations in either daily life activities or sociocultural patterns. The importance of rib fractures analysis, as Brickley (2006) demonstrated, is incontestable as a complement for the understanding of past societies.

Even modern medical practice takes advantage of the predictive value of ribs fractures as indicators of lifestyles or specific circumstances such as cases of chronic alcoholism patients (González-Reimers et al., 2005) or abused children (Lonergan et al., 2003; Resnick and Goergen, 2005), specially in those under 2 years old (Kemp et al., 2006). Moreover, since the rib cage protects important and vital organs and vessels (DiMaio and DiMaio, 2001), fractured ribs are of great significance with regard to their associated morbidity and mortality rates, especially in older individuals (Ziegler and Agarwal, 1994; Bulger at al., 2000; Holcomb et al., 2003).

The question is whether the rates of mortality and morbidity due to rib fractures were even higher in past times, when neither therapeutics nor effective medical care existed. The answer to this is challenging to paleopathologists because the analysis of well healed rib fractures cannot by itself provide full information about the cause of death of the individuals and determining their possible etiology is one of the osteologist's biggest challenges. The cause of death assessment is virtually indeterminable based exclusively on skeletal evidence (DiMaio and DiMaio, 2001; Cunha, 2006; Rodríguez-Martín, 2006), although perimortem rib fractures occasionally provide useful information concerning "manner of death" (Sauer, 1998; Cunha, 2006; Rodríguez-Martín, 2006). This type of fracture is difficult to detect in skeletal material and the majority of fractures reported from paleopathological and forensic contexts are those with noticeable evidence of bony repair at the site where breakage took place (Cunha and Pinheiro, 2005/2006; Moraitis and Spiliopoulou, 2006). This indicates survival of the individual, at least for some days or weeks (Lovell, 1997), after the injury. The healing stage of a fracture is considered as being correlated with the time interval between death and the moment the injury was inflicted (DiMaio and DiMaio, 2001; Prosser et al., 2005), and can provide useful information both for paleopathological and forensic studies.

Direct or indirect blunt chest traumas are the major causes of rib fractures (Marmor, 1969; DiMaio and DiMaio, 2001; Liman et al., 2003), but these may also occur as a consequence of biomechanical stress induced in sport activities (Iwamoto and Takeda, 2003; Connolly and Connolly, 2004) such as rowers (Warden et al., 2002; Iwamoto and Takeda, 2003), or in individuals suffering from severe and prolonged coughing (Kawahara et al., 1997; Litch and Tuggy, 1998; Maeseneer et al., 2000; Hanak et al., 2005; Hillenbrand et al., 2006). However, rib biomechanics is generally poorly understood (Love and Symes, 2004) and the "anthropological literature seems to be as limited as the medical literature on thorax bone injury" (Love and Symes, 2004, p 1153). Consequently, while analyzing rib fracture patterns from skeletal material, the reconstruction of their underlying traumatic events is a difficult and challenging task.

The main goals of this investigation are: 1) to report rib fractures prevalence and patterns in a sample of skeletons belonging to identified individuals who lived between the late 19th and the early-middle 20th centuries, a period before the advent of antibiotics in Portugal; 2) to provide comparative data for future studies dealing with rib fractures, both from archeological and forensic investigations; 3 ) to compare the results with both modern epidemiological data and analogous paleopathological investigations; 4) to investigate the relationship between cause of death and rib fracture prevalence. In fact, modern clinical evidence shows that pulmonary complications are a common outcome of rib fractures (Ziegler and Agarwal, 1994; Bulger et al., 2000; Holcomb et al., 2003; Sirmali et al., 2003; Flagel et al., 2005), which, inversely, may be provoked by coughing induced by underlying respiratory diseases (Kawahara et al., 1997; Hanak et al., 2005; Hillenbrand et al., 2006). This puzzling scenario of rib fractures, which can be either the origin or the outcome, is demanding for those studying human skeletal remains. Based on this dual aetiology of rib fractures and considering that coughing induced by pulmonary diseases, such as pulmonary tuberculosis (TB) (Hopewell, 1994), would have been even more prolonged and intense in the preantibiotic era than it is today, it can be hypothesized that there was a higher prevalence of rib fractures in the individuals who died from pulmonary diseases in the past. These objectives will be accomplished by presenting and discussing the results from the study of a sample belonging to the human identified skeletal collection from the Museu Bocage (National Museum of Natural History, Lisbon), composed of individuals who lived and died in the Portuguese capital, Lisbon, between the late 19th and earlymiddle 20th centuries.

\section{MATERIALS AND METHODS}

The sample was selected from the human identified skeletal collection (also known as the "Lisboa collection") housed at the Department of Zoology and Anthropology (Museu Bocage) from the National Museum of Natural History, Lisbon. This osteological series comprises the bony remains of 1,692 identified skeletons that came from three Lisbon cemeteries (Alto de São João, Benfica and Prazeres) and, according to Cardoso (2006, p 174), "the process of skeletal collecting is still in progress." Currently, 699 individuals have complete biographical information available (such as name, age at death, place of birth, occupation, place of residence, and date and cause of death). This collection is mainly composed of the skeletal remains of people who belonged to the lower and middle socioeconomic strata of Lisbon inhabitants who were born between 1805 and 1972 and died in Lis- 
bon between 1880 and 1975 (Cardoso, 2006). In this investigation the causes of death registered for these individuals were coded using the internet version of the 10th revision of the International Classification of Diseases (ICD-10) from the World Health Organization (2006). This procedure was done to update and standardize the causes of death terminology, as these are written in the original records according to the medical terms used in Portugal in the first half of the 20th century, some of which are no longer used or used interchangeably to refer to the same disease. Additionally, ICD-10 is a free universal standardized classification and can be used by other researchers allowing future comparisons.

This study comprised a total of 197 individuals, 109 males, and 88 females, born between 1819 and 1941 and who died between 1881 and 1959. Ages at death ranged from 13 to 88 years old with a mean of 45.7 and median of 44 years. Sampling methodology and design, namely the sample demographic and epidemiological profiles, were previously reported by Matos (2003) and Matos and Santos (2006). The sample included all the 133 individuals who died from pulmonary disease, namely 84 who died from pulmonary TB and 49 from other pulmonary nontuberculous conditions. The remaining 64 individuals, i.e. the control group, were randomly selected from those with an extra-pulmonary nontuberculous cause of death.

All the ribs present, either complete or fragmented, were sided and numbered according to the standard published methods (Aiello and Dean, 1990; Dudar, 1993; Mann, 1993; Bass, 1997; Hoppa and Saunders, 1998; White, 2000; Owers and Pastor, 2005). Macroscopic observation was performed taking into account the identification of fractures based on the presence of: 1) angular deformity; 2) apposition of bone; 3) healing or wellhealed, but still noticeable, bony callus. Fractures were quantified and described in detail for each of the rib anatomical regions: sternal and vertebral ends, and shaft.

The term fracture is used in the present work to designate any partial or complete break in the continuity of a bone, a broad definition adopted in the medical practice (Resnick and Goergen, 2005) and during human skeletal remains analysis from archaeological and forensic contexts (Lovell, 1997; Aufderheide and Rodríguez-Martín, 1998; DiMaio and DiMaio, 2001; Ortner, 2003; Roberts and Manchester, 2005; Rodríguez-Martín, 2006). The positive identification of a rib fracture was only considered when unequivocal healing was observed, i.e., when in the presence of a callus composed of new bone (woven and/or lamellar) (Lovell, 1997), with or without fusion of the fractured ends.

The assessment of the fracture type and the distinction between antemortem and postmortem fractures followed the definitions compiled and summarized by Lovell (1997) and took into consideration the guidelines for fracture recording proposed by Buikstra and Ubelaker (1994) and Roberts and Connell (2004). Although the identification of perimortem fractures is a very important issue both in paleopathology and in forensic anthropology, especially in the analysis and interpretation of injuries related to violent events (Sauer, 1998; Walker, 2001; Simmons and Haglund, 2005; Cunha and Pinheiro, 2005/2006; Rodríguez-Martín, 2006), their assessment in the skeletal record is often impossible (Grauer and Roberts, 1996; Lovell, 1997). Thus, in the present investigation perimortem fractures were not systematically analyzed and only considered as present in unequivocal cases (i.e. when bony repair, composed of woven bone, was observed in the region where the fracture took place).

Radiographs were performed in doubtful cases, namely when healing calluses were remodeled to the extant that the presence of a fracture was difficult to detect based exclusively on naked eye observation. Ribs were radiographed anteroposteriorly and mediolaterally at the Hospitais da Universidade de Coimbra, using the following equipment: mammographer General Electric, Senographe DMR model (technical specifications: $28 \mathrm{KV} ; 20$ $\mathrm{mAs} ; 660 \mathrm{~mm})$. All statistical analyses were performed using SPSS version 14.0 (SPSS, 2005) and EpiInfo, version 3.3.2 (Center for Disease Control, 2005). A significance level of $\leq 0.05$ was used for all tests: Chi-square test, Pearson correlation, Kolmogorov-Smirnov test, Student $t$ test and One-way ANOVA.

\section{RESULTS \\ Preservation and representativity of the ribs}

A total of 4,276 ribs from the 197 individuals were studied, representing $90.4 \%$ of the total number of ribs expected (i.e. 4,728, assuming the existence of 12 pairs of ribs for each individual) and a mean of 21.7 ribs per individual. The number of ribs present by individual ranged from 4 to 24 , but the large majority, i.e. $87.3 \%$ (172/197), had 20 or more ribs preserved.

The Table 1 shows the frequency of ribs studied by side and order in the thoracic cage. A high representation of each rib pair was found $(\geq 85.3 \%)$ except for the 12 th $(52.8 \%$ and $54.8 \%$, respectively for the left and right sides). Left and right ribs were equally represented. This high representation of ribs was also observed across the three anatomical regions (see Fig. 1): $99.3 \%(4,248 / 4,276)$ for vertebral ends, $97.8 \%(4,181 /$ $4,276)$ for shafts and $82.8 \%(3,542 / 4,276)$ for sternal ends. In practical terms, these results demonstrate that the majority of the rib sets under study were essentially complete.

In a few cases the surfaces of the entire rib, or specific rib regions, were partially unobservable due to one or more of the following reasons: 1) incomplete process of skeletonization with the persistence of organic materials such as small pieces of dried soft tissues (probably muscle fibers) or the presence of fabric fibers adhering to ribs, eventually remnants of the cadaver's clothes; 2) postmortem changes, such as exfoliation of the external surface of the rib cortex, mainly due to the action of taphonomic agents such as water, plant roots, animals, soil properties, among other extrinsic and intrinsic factors commonly influencing the decomposition of the cadaver (Henderson, 1987; Sledzik, 1998; Botella et al., $2000)$; 3) changes with an anthropic origin were also noted, namely in 10 individuals (5.1\% out of 197) whose sternal ends of the ribs were missing due, most certainly, to autopsy procedures. In specific cases it was even possible to observe the sternal rib fragments resulting from the cutting procedures during the autopsy, but it was not possible to know their respective rib number (see Fig. 2).

\section{The overall prevalence of rib fractures}

In the 197 individuals observed, 47 (23.9\%) presented at least one fractured rib. Considering the overall prevalence by sex, men were more affected than women (Table 2 ), presenting a higher mean and standard deviation of 
TABLE 1. Frequency of the ribs observed and fractured by laterality, and according to their order in the rib cage

\begin{tabular}{|c|c|c|c|c|c|c|c|c|c|c|c|c|}
\hline \multirow{3}{*}{$\begin{array}{c}\text { Rib } \\
\text { number }\end{array}$} & \multicolumn{4}{|c|}{ Left } & \multicolumn{4}{|c|}{ Right } & \multicolumn{4}{|c|}{ Total } \\
\hline & \multicolumn{2}{|c|}{ Observed } & \multicolumn{2}{|c|}{ Fractured } & \multicolumn{2}{|c|}{ Observed } & \multicolumn{2}{|c|}{ Fractured } & \multicolumn{2}{|c|}{ Observed } & \multicolumn{2}{|c|}{ Fractured } \\
\hline & $n$ & $\%^{\mathrm{a}}$ & $n$ & $\%$ & $n$ & $\%^{a}$ & $n$ & $\%$ & $n$ & $\%^{a}$ & $n$ & $\%$ \\
\hline 1 & 182 & 92.4 & 2 & 2.6 & 178 & 90.4 & 1 & 2.1 & 360 & 91.4 & 3 & 2.4 \\
\hline 2 & 193 & 98.0 & 4 & 5.3 & 193 & 98.0 & 4 & 8.5 & 386 & 98.0 & 8 & 6.5 \\
\hline 3 & 194 & 98.5 & 7 & 9.2 & 194 & 98.5 & 5 & 10.6 & 388 & 98.5 & 12 & 9.8 \\
\hline 4 & 194 & 98.5 & 3 & 3.9 & 196 & 99.5 & 6 & 1.8 & 390 & 99.0 & 9 & 7.3 \\
\hline 5 & 192 & 97.5 & 9 & 11.8 & 185 & 93.9 & 3 & 6.4 & 377 & 95.7 & 12 & 9.8 \\
\hline 6 & 188 & 95.4 & 9 & 11.8 & 182 & 92.4 & 2 & 4.3 & 370 & 93.9 & 11 & 8.9 \\
\hline 7 & 189 & 95.9 & 9 & 11.8 & 186 & 94.4 & 4 & 8.5 & 375 & 95.2 & 13 & 10.6 \\
\hline 8 & 183 & 92.9 & 12 & 15.8 & 183 & 92.9 & 8 & 17.0 & 366 & 92.9 & 20 & 16.3 \\
\hline 9 & 180 & 91.4 & 7 & 9.2 & 178 & 90.4 & 7 & 14.9 & 358 & 90.9 & 14 & 11.4 \\
\hline 10 & 178 & 90.4 & 7 & 9.2 & 175 & 88.8 & 2 & 4.3 & 353 & 89.6 & 9 & 7.3 \\
\hline 11 & 173 & 87.8 & 5 & 6.6 & 168 & 85.3 & 5 & 10.6 & 341 & 86.5 & 10 & 8.1 \\
\hline 12 & 104 & 52.8 & 2 & 2.6 & 108 & 54.8 & 0 & 0 & 212 & 53.8 & 2 & 1.6 \\
\hline Total & 2,150 & 90.9 & 76 & 61.8 & 2,126 & 89.9 & 47 & 38.2 & 4,276 & 90.4 & 123 & 100.0 \\
\hline
\end{tabular}

a These percentages were calculated assuming the existence of 12 rib pairs for each individual.

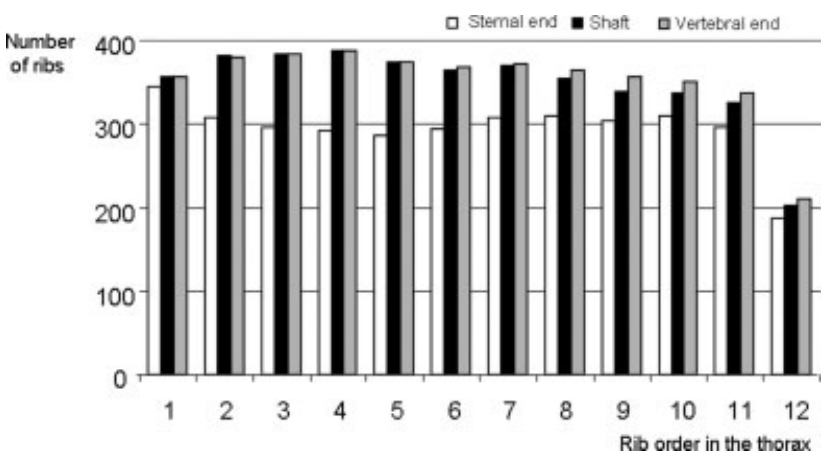

Fig. 1. Representativity of the anatomical regions in the 4,276 rib observed.

rib fractures by individual $(\bar{x}=3.08$ and s.d. $=2.65$ for men; $\bar{x}=2.15$ and s.d. $=1.75$ for women). However, sex differences in the prevalence of rib fractures were not statistically significant (Yates corrected $\chi^{2}=0.03 ; 1 \mathrm{df} ; P$ $=0.868$ ). The frequency of rib fractures (Table 2) was significantly higher in older individuals $\left(\chi^{2}\right.$ for the trend $=16.294 ; 1 \mathrm{df} ; P<0.01)$ and a positive correlation was found between the prevalence of affected individuals and age classes (Pearson correlation: $R^{2}=0.288 ; P<0.01$ ). This trend is also evident when the mean ages at death between individuals with $(56$, s.d. $=18.4)$ and without $(41$, s.d. $=20.9)$ rib fractures are compared, differences that are highly significant ( $t$ test: $t=-4.173 ; 196 \mathrm{df}$; $P<0.001)$. This difference remains significant when the sample structure is adjusted for age ( $t$ test: $t=-23.986$; 6636.5 df; $P<0.001$ ).

In the 4,276 ribs studied $123(2.9 \%)$ revealed at least one fracture. When the prevalence of fractures by side is considered (see Table 1) the left ribs are more affected $(61.8 \%$ [76/123]) than the right ones (38.2\% [47/123]). One individual (sk. 777) was excluded from these calculations due to the near absence of ribs. For most individuals the unilateral location of rib fractures was the most common condition $(70.2 \%$ [33/47]) and the left thoracic wall was more affected than the right (Table 3 ). The first and twelfth ribs were least affected. Conversely, the eighth rib from both sides was the most fractured (Table 1 ). The middle thoracic ribs (5-8th) accounted for $45.5 \%$ (56 out of 123) of the fractures. When ribs were analyzed

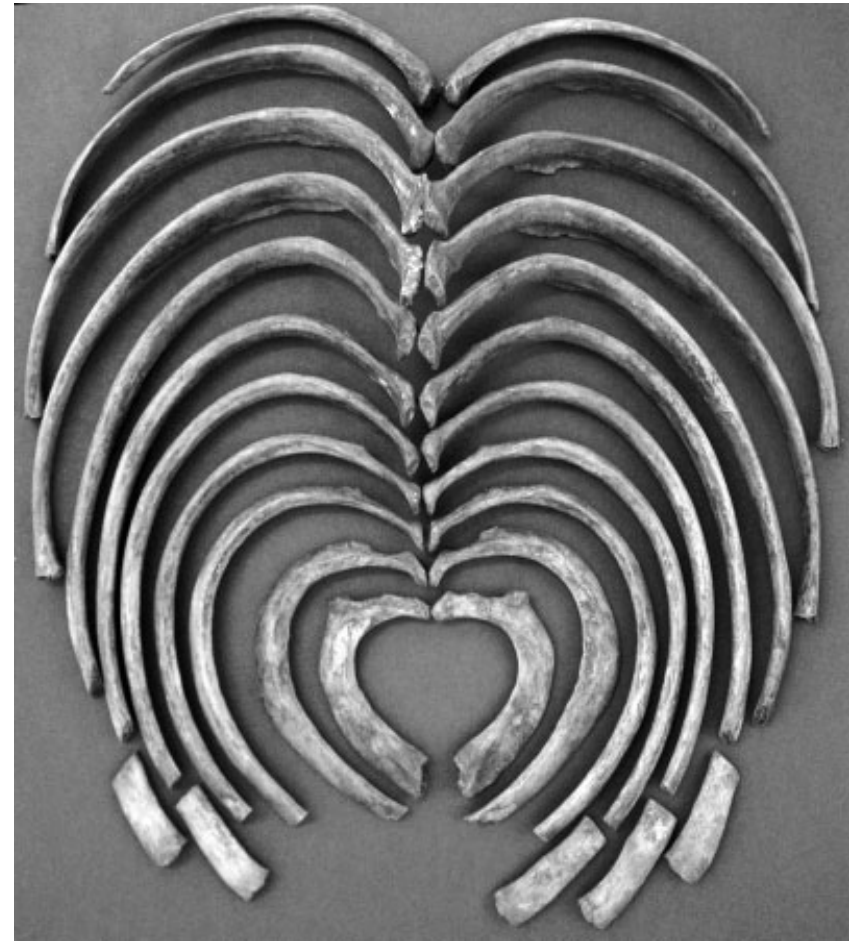

Fig. 2. Costal set of skeleton number 506 (male, 30 year old, cause of death: heart injury caused by a firearm, "Ferida do coração por arma de fogo" - S26.9 group from ICD-10) showing autopsy signs at the rib sternal ends.

according to their anatomical regions (Gray, 1995), the true or vertebro-sternal ribs (1st to 7 th) were the most fractured (55.3\% [68/123]) followed by the vertebro-chondral ribs (8-10th) $(35.0 \%$ [43/123]) and then by the floating ribs (11-12th) $(9.7 \%$ [12/123]). Taking into consideration the anatomical zones of the ribs notable patterns observed were: 1) 38 out of 46 affected individuals $(82.6 \%)$ presented rib fractures exclusively confined to a single anatomical region, with the shaft (corresponding to the lateral part of the rib cage) the most affected zone (29 individuals), followed by the sternal end (anterior rib cage) (eight cases) and the vertebral extremity (posterior rib cage) (one individual); 2) two or more rib zones were 
TABLE 2. Distribution of the 197 individuals, both with and without rib fractures, by sex and age classes

\begin{tabular}{|c|c|c|c|c|c|c|c|c|c|c|c|}
\hline \multirow[b]{2}{*}{ Rib fractures } & \multirow[b]{2}{*}{ Sex } & \multicolumn{8}{|c|}{ Age classes (years) } & \multirow{2}{*}{\multicolumn{2}{|c|}{ Total }} \\
\hline & & $12-20$ & $21-30$ & $31-40$ & $41-50$ & $51-60$ & $61-70$ & $71-80$ & $81-88$ & & \\
\hline \multirow[t]{3}{*}{ Absent } & Male & 13 & 19 & 13 & 19 & 7 & 6 & 3 & 3 & 83 & $55.3 \%$ \\
\hline & Female & 10 & 18 & 6 & 7 & 4 & 9 & 7 & 6 & 67 & $44.7 \%$ \\
\hline & Total & 23 & 37 & 19 & 26 & 11 & 15 & 10 & 9 & 150 & $76.1 \%$ \\
\hline \multirow[t]{3}{*}{ Present } & Male & 0 & 2 & 2 & 6 & 4 & 6 & 5 & 1 & 26 & $55.3 \%$ \\
\hline & Female & 1 & 2 & 2 & 4 & 1 & 6 & 3 & 2 & 21 & $44.7 \%$ \\
\hline & Total & 1 & 4 & 4 & 10 & 5 & 12 & 8 & 3 & 47 & $23.9 \%$ \\
\hline Total & & 24 & 41 & 23 & 36 & 16 & 27 & 18 & 12 & 197 & \\
\hline
\end{tabular}

TABLE 3. Distribution of the 47 individuals with rib fractures, both with isolated and adjacent broken ribs, according to rib cage laterality

\begin{tabular}{lrrrcc}
\hline \multirow{2}{*}{$\begin{array}{c}\text { Laterality of } \\
\text { fractures }\end{array}$} & \multicolumn{2}{c}{ Individuals } & & \multicolumn{2}{c}{ Adjacent broken ribs } \\
\cline { 2 - 3 } \cline { 5 - 6 } & $n$ & $\%$ & & Present & Absent \\
\hline Unilateral left & 19 & 40.4 & & 8 & 11 \\
Unilateral right & 14 & 29.8 & & 2 & 12 \\
Unilateral total & 33 & 70.2 & & 10 & 23 \\
Bilateral & 13 & 27.7 & & 9 & 4 \\
Undetermined & 1 & 2.1 & & - \\
Total & 47 & 100.0 & & $19(41.3 \%)$ & $27(58.7 \%)$ \\
\hline
\end{tabular}

fractured in 8 of 46 individuals (17.4\%), five of which were affected in two zones and the other three in all three regions considered.

The number of fractured ribs ranged from 1 to 8 by individual (Table 4), with a mean of 2.67 (s.d. = 2.33; median $=2$; mode $=1$ ). Twenty five individuals had two or more fractured ribs (54.3\% of 47 ) (Table 5). Within this group were 19 individuals $(41.3 \%)$ with two or more adjacent ribs involved. The range of adjacent rib involvement varied from 2 to 7 ribs, with a mean of 3.1 for the left side and 2.6 for the right one. In four individuals adjacent broken ribs were found bilaterally (sks. 70, 119, 257, 270). Multiple fractures occurring on the same rib (see Fig. 3) were recorded (Table 5) in a total of seven ribs belonging to three individuals (sks. 53, 119, 257).

\section{Rib fractures and causes of death}

When causes of death were considered under the ICD10 codification, as expressed in Table 6 , the most affected cause of death categories (ICD-10) were those from the neoplasms group (C00-D48), which presented the highest prevalence of individuals with broken ribs (42.9\% [3/7]), followed by the Genitourinary system group (N00-N99) with 1 individual affected $(33.3 \%$ out of 3$)$ and then by the respiratory system (pulmonary tuberculosis excluded) group (J00-J99) with 14 individuals affected (29.8\% out of 47 ). The Pulmonary TB group (A15-A19) prevalence $(23.8 \%$ [20/84]) was ranked in the fifth position behind to the Certain infectious and parasitic diseases (TB excluded) group (A00-B99) (28.6\% [2/7]). The prevalence of rib fractures in the three remaining affected groups ranged between $21.1 \%$ (4 out of 19 individuals from the Heart and circulatory diseases group, I00-I99) and $16.7 \%$ (1 out of 6 individuals from the Nervous systems diseases, G00-G99). The four remaining groups (D50-D89, P00-Q99, R00-R99, and S00-T98) had no individuals presenting rib fractures (Table 6). It must be emphasized that some of the above prevalences are not statistically meaningful due to the small number of individuals composing some of the groups. This is the case, for example, in the neoplasms group (C00-D48) and in the genitourinary system group (N00-N99), both presenting the highest prevalence of rib factures.

Of the sample of 47 individuals with rib fractures, $72.3 \%$ ( $n=34)$ died from some form of pulmonary disease (A15-A19 and J00-J99 ICD-10 groups). However, this apparent correlation between rib fractures and pulmonary disease is more reflective of the sample composition than any actual relationship between these two conditions. If the proportion of individuals with fractured ribs is evaluated in light of the total number of individuals in each cause-of-death group (Table 6), no significant differences are apparent in the frequency of rib fractures in the pulmonary group $(26.0 \%$ [34/131]) relative to the nonpulmonary group $\left(19.7 \%\right.$ [13/66]) (Yates corrected $\chi^{2}$ $=0.656 ; 1 \mathrm{df} ; P=0.418$ ).

In order to explore patterns of rib fractures, the affected individuals were further grouped into four categories: pulmonary TB; pneumonia; pulmonary diseases other than TB and pneumonia and nonpulmonary diseases. It was tested if differences were noticeable between these groups concerning the mean number of rib fractures and the respective standard deviation. The group composed from individuals who died from pneumonia presented higher mean values of rib fractures (3.7) (see Fig. 4) as well as a higher standard deviation value (3.02). Although not significant (One-way ANOVA: $F=$ $1.286 ; P=0.292$ ) these values contrast with those calculated for the remaining groups $(2.37,1.25$, and 2.77 respectively for the pulmonary TB group, pulmonary diseases other than TB and pneumonia group, and nonpulmonary diseases group). These slight differences were still noticeable after age adjustment of the sample structure. Further, the pulmonary TB and pneumonia groups are by far the leading ones when two or more ribs fractured by individual were noticed (Table 7).

Sixteen $(34.0 \%)$ of 47 individuals presenting rib fractures had at least one fractured rib with noticeable woven bone associated with the fracture site, indicating an early healing stage and a relatively recent fracture (Table 7). This is the case for individual number 1139, a 70 years old male who died from pulmonary TB, who presented woven bone along the nonfused broken margins of the middle shaft of the sixth left rib (see Fig. 5). This skeleton also presented remodeled rib fractures located on the middle diaphyseal portion of the second, third, and fourth right ribs, indicating different healing stages, and probably different traumatic events. Thirteen of these individuals belongs to the pulmonary group of causes of death (9.8\% out of 133 ): seven who died from pulmonary TB (sks. 233, 1092, 1139, 1182, 1227, 1251, 1422) and six who died from other non-TB pulmonary diseases ("pneumonia": sks. 270, 376, 564, 1435; "bronchitis": sk. 1172; "pulmonary edema": sk. 1123). From the three remaining cases $(4.7 \%$ [3/64]), belonging to the nonpulmonary group of causes of death, two died from 
TABLE 4. Distribution of the individuals with rib fractures according to the number of broken ribs, by sex and age classes

\begin{tabular}{|c|c|c|c|c|c|c|c|c|c|c|c|c|}
\hline \multirow{2}{*}{$\begin{array}{l}\text { Number of } \\
\text { broken ribs }\end{array}$} & \multicolumn{2}{|c|}{ Individuals } & \multicolumn{2}{|c|}{$\operatorname{Sex}(n)$} & \multicolumn{8}{|c|}{ Age classes (years) } \\
\hline & $\bar{n}$ & $\%$ & Males & Females & $12-20$ & $21-30$ & $31-40$ & $41-50$ & $51-60$ & $61-70$ & $71-80$ & $81-88$ \\
\hline 1 & 21 & 45.65 & 11 & 10 & 0 & 1 & 3 & 6 & 4 & 3 & 3 & 1 \\
\hline 2 & 10 & 21.74 & 6 & 4 & 0 & 0 & 1 & 1 & 1 & 3 & 3 & 1 \\
\hline 3 & 4 & 8.70 & 0 & 4 & 1 & 1 & 0 & 0 & 0 & 1 & 1 & 0 \\
\hline 4 & 3 & 6.52 & 3 & 0 & 0 & 1 & 0 & 0 & 0 & 2 & 0 & 0 \\
\hline 5 & 1 & 2.17 & 0 & 1 & 0 & 1 & 0 & 0 & 0 & 0 & 0 & 0 \\
\hline 7 & 3 & 6.52 & 3 & 0 & 0 & 0 & 0 & 2 & 0 & 0 & 1 & 0 \\
\hline 8 & 4 & 8.70 & 3 & 1 & 0 & 0 & 0 & 1 & 0 & 2 & 0 & 1 \\
\hline Total & 46 & 100.0 & 26 & 20 & 1 & 4 & 4 & 10 & 5 & 11 & 8 & 3 \\
\hline
\end{tabular}

"cerebral hemorrhage" (sk. 70, 156) and one from "heart failure" (sk. 53). Nonsignificant differences were found $\left(\chi^{2}=1.06 ; 1 \mathrm{df} ; P=0.303\right)$ between the pulmonary and nonpulmonary groups of cause of death when healing rib fractures were considered. However, a specific pattern consisting on the simultaneous presence of healing rib fractures and adjacent broken ribs at the same individual was found to be much more common in those who died from pneumonia (14.3\% [4/28]). Lower frequencies of this pattern were calculated for the remaining causeof-death groups: $3.6 \%$ (3/84) from the pulmonary TB, none amongst the 21 individuals from the pulmonary diseases other TB and pneumonia group, and 3.1\% (2/64) from the nonpulmonary causes of death.

\section{DISCUSSION \\ The overall prevalence of rib fractures}

Although rib fractures are referred to in the paleopathological literature as being a common finding (Lovell, 1997; Aufderheide and Rodríguez-Martín, 1998; Jurmain, 1999; Campillo, 2001; Ortner, 2003; Roberts and Cox, 2003; Roberts and Manchester 2005; Brickley, 2006) there is a scarcity of published reports on their prevalence, making comparative analysis and interpretation difficult. The evidence from the available studies (Table 8) reveals that the reported prevalence of rib fractures by individual-the crude prevalence rate-ranges between 5.2\% (Curate, 2007) and 31.3\% (Garcia, 2007). Thus, the result from the present study, $23.9 \%$ of the individuals presenting rib fractures, indicates that prevalence of broken ribs in the study sample was one of the highest reported. A great variability between studies was also noted for the true prevalence rate, i.e. the proportion of ribs fractured in the total number of all ribs observed, this ranging from 2.3\% (138/5975) (Brickley, $2006)$ to $6.4 \%$ (66/1025) (Garcia, 2007). Intermediary values for this rate were found in the study performed by Assis (2007) $-4.8 \%$ of ribs fractured out of 498 ribs observed-and in the review made by Roberts and Cox (2003) for British archeological material-respectively $3.6 \%$ (of 4,393 ) for the late medieval period and $4.2 \%$ (of $2,081)$ for the postmedieval one. In the context of the paleopathological literature the true prevalence rate of $2.9 \%(123 / 4,276)$ calculated for the present study is low.

The meaning and interpretation of these rates in osteological surveys are not always straightforward as these depend firstly on the demographic profile of the sample being analyzed and secondly on the differential action of taphonomical and anthropogenic agents as well as on excavation techniques and recovery conditions. In fact, true prevalence rates are highly influenced by the representativeness and preservation of the ribs. This is often a neglected issue in the analysis of skeletal remains despite the importance of the differential survival of bones for accurate estimates of disease prevalence in the past (Waldron, 1987). Within the few examples of bioarcheological investigations reporting rib preservation figures are, for example, the study of Waldron (1987), who stated that $40-59 \%$ of expected numbers of ribs were preserved, and of Bello et al. (2006) who found a great variability in rib preservation in three skeletal series.

The postmortem survival of ribs is generally poor, especially when compared with other skeletal elements (Waldron, 1987; Bello et al., 2006). However, the real figures of rib preservation are rarely reported, mainly because the majority of the researchers avoid their systematic study due to two major reasons: first, rib identification, siding and numbering are time consuming tasks, that also require some training; second, there is, as Brickley (2006, p 68) states, a more conceptual than real "general perception that ribs are often very badly preserved" in archaeological material. Thus, the high representativeness $(90.4 \%$ out of 4,728 expected to observe) and completeness (see Fig. 1) of the ribs reported for the present study are uncommon figures in the context of human remains analysis. There are several facts that could explain the excellent preservation in this sample: 1) the short time period (less than one century) between the inhumation of the individuals and the exhumation of their skeletons, contrasting with the skeletal material derived from archaeological contexts; 2) careful rib exhumation by the cemetery workers, contrary to what happened to nonadult bones and small adult ones, which according to Cardoso (2005, p 42) were "completely overlooked."

Age and sex differences in the context of traumarelated fractures of the cranial and long bone are well documented in the paleopathological record (Grauer and Roberts, 1996; Lovell, 1997) and their analysis and interpretation usually includes as many variables as possible, especially those related to the sociocultural context where the sample comes from (Lovell, 1997; Walker, 2001). The information concerning rib fracture prevalence also should be included in any trauma related fractures analysis. In the present study men were slightly more affected by rib fractures $(55.3 \%)$ than women $(44.7 \%)$, although these sex differences were not significant. Although interpopulation comparisons of both demographic and epidemiological profiles of skeletal populations are difficult (Glencross and Sawchuk, 2003; Waldron, 2007), these results are in accordance with those reported for similar studies (Robledo and Trancho, 1999; Brickley, 2006; Assis, 2007; Curate, 2007; Garcia, 


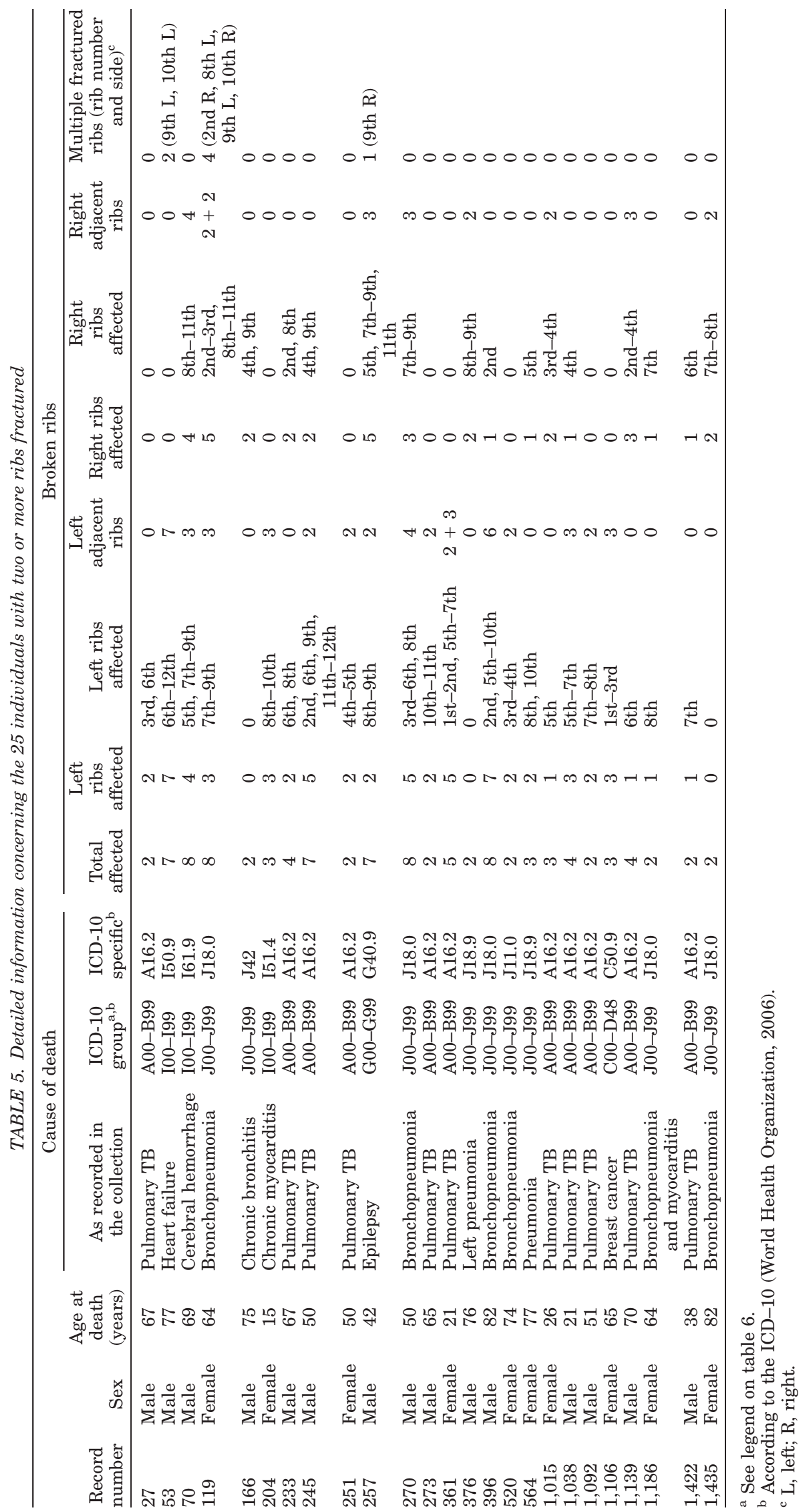




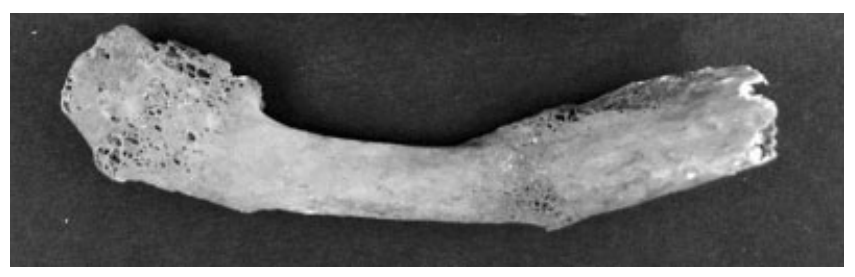

Fig. 3. Multiple fractures, at the vertebral end and shaft, of the 10th right rib from the skeleton number 119 (female, 64 years old, cause of death: bronchopneumonia - J18.0 group from ICD-10).

TABLE 6. Distribution of the individuals observed by groups of cause of death according to the ICD-10 codification (World Health Organization, 2006)

\begin{tabular}{|c|c|c|c|c|c|}
\hline \multirow{3}{*}{$\begin{array}{l}\text { ICD-10 groups of } \\
\text { cause of death }^{\mathrm{a}}\end{array}$} & \multirow{2}{*}{\multicolumn{2}{|c|}{$\begin{array}{l}\text { Individuals } \\
\text { observed } \\
(N)\end{array}$}} & \multicolumn{3}{|c|}{$\begin{array}{l}\text { Individuals with } \\
\text { rib fractures }(n)\end{array}$} \\
\hline & & & \multirow[b]{2}{*}{$n$} & \multirow{2}{*}{$\begin{array}{l}\% \text { between } \\
\text { groups } \\
\text { (n/total } \\
\text { affected) }\end{array}$} & \multirow{2}{*}{$\begin{array}{c}\text { \% within } \\
\text { groups } \\
(n / N)\end{array}$} \\
\hline & $N$ & $\%$ & & & \\
\hline \multicolumn{6}{|l|}{ Pulmonary } \\
\hline A15-A19 & 84 & 42.6 & 20 & 42.6 & 23.8 \\
\hline J00-J99 & 47 & 23.9 & 14 & 29.8 & 29.8 \\
\hline Total & 131 & 66.5 & 34 & 72.3 & 26.0 \\
\hline \multicolumn{6}{|l|}{ Non-pulmonary } \\
\hline I00-I99 & 19 & 9.6 & 4 & 8.5 & 21.1 \\
\hline K00-K93 & 9 & 4.6 & 2 & 4.3 & 22.2 \\
\hline R00-R99 & 7 & 3.6 & 0 & 0 & 0 \\
\hline A00-B99 & 7 & 3.6 & 2 & 4.3 & 28.6 \\
\hline C00-D48 & 7 & 3.6 & 3 & 6.4 & 42.9 \\
\hline S00-T98 & 6 & 3.0 & 0 & 0 & 0 \\
\hline G00-G99 & 6 & 3.0 & 1 & 2.1 & 16.7 \\
\hline N00-N99 & 3 & 1.5 & 1 & 2.1 & 33.3 \\
\hline D50-D89 & 1 & 0.5 & 0 & 0 & 0 \\
\hline P00-Q99 & 1 & 0.5 & 0 & 0 & 0 \\
\hline Total & 66 & 33.5 & 13 & 27.7 & 19.7 \\
\hline Overall total & 197 & 100.0 & 47 & 100.0 & 23.9 \\
\hline
\end{tabular}

a Legend: A15-A19, Pulmonary tuberculosis; J00-J99, Respiratory system diseases; I00-I99, Heart and circulatory diseases; K00-K93, Digestive system diseases; R00-R99, General symptoms and signs or unknown cause of death; A00-B99, Certain infectious and parasitic diseases, tuberculosis excluded; $\mathrm{CO0}$ D48, Neoplasms; S00-T98, Injury, poisoning and other consequences of external causes; G00-G99, Nervous system diseases; N00-N99, Genitourinary system diseases; D50-D89, Blood and blood-forming organs and certain disorders involving the immune mechanism; P00-Q99, Pregnancy, childbirth and the puerperium.

2007; Jordana, 2007), which reveal a higher proportion of men affected. The significantly higher prevalence of rib fractures and number of ribs affected by individual in the older individuals from the sample analyzed does not differ from that reported in analogous investigations (Brickley, 2006; Curate, 2007). Age can be an important confounder when calculating the prevalence of diseases in the past (Waldron, 2007), since older individuals will have a higher probability of having experienced skeletal injury during life and will accumulate more fractures than younger ones (Glencross and Sawchuk, 2003). In the present study, rib fractures were more prevalent in older individuals with or without adjustment of the sample age structure. Whether this higher prevalence of rib fractures in older individuals results from the accumula-

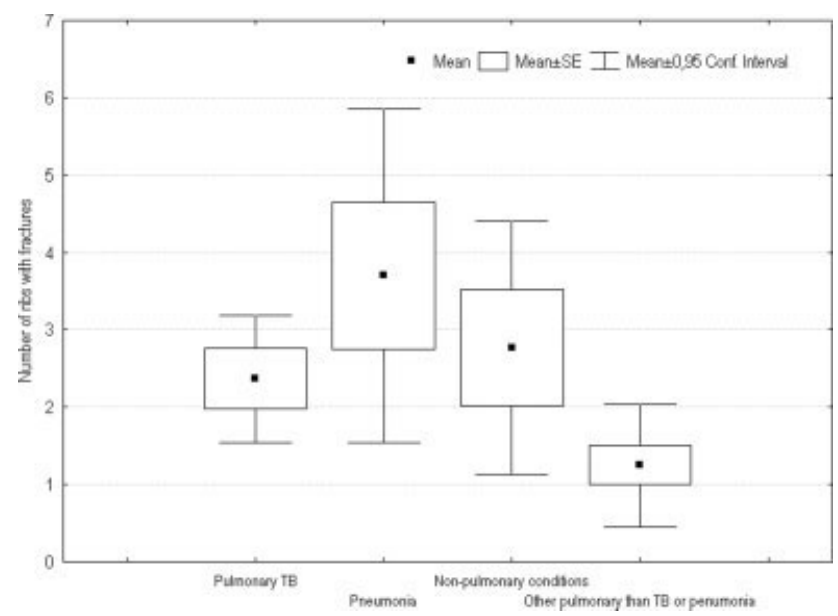

Fig. 4. Mean number of rib fractures by "artificial" categories of cause of death.

tion of fractures during life or results from specific phenomena, such as traumatic events or underlying bone disease, remains unclear. Curate (2007) analyzed a sample from the Coimbra identified skeletal collection contemporary to the "Lisboa collection" and reported a significantly higher mean age at death for those individuals with rib fractures. Whether this association is related to age-related bone loss, or even to osteoporosis occurring in older women remains controversial both for present (Frost, 2003; Seeman and Delmas, 2006; Sievänen et al., 2007) and past populations (Brickley, 2002; Grynpas, 2003; Agarwal et al., 2004; Mays, 2006).

In the context of modern medical practice rib fractures are very common injuries and isolated rib cage trauma comprises around 10-15\% of admissions to the hospital trauma services (Ziegler and Agarwal, 1994; Bulger et al., 2000; Holcomb et al., 2003; Sirmali et al., 2003; Flagel et al., 2005). The high mortality and morbidity rates in older patients presenting rib fractures are well documented in the medical literature (Bulger et al., 2000; Holcomb et al., 2003; Sirmali et al., 2003; Victorino et al., 2003) and a similar scenario was certainly occurring in the past and needs more attention from paleopathologists. The overall prevalence of rib fractures obtained for each of the paleopathological studies described above is difficult to interpret in the light of actual sociocultural standards and almost impossible to compare with the modern clinical evidence. This is because past living conditions were certainly very different than today, even for most recent individuals such as those in the "Lisboa collection," who lived and died between the late 19th-early-middle 20th centuries, when no effective treatment existed for the majority of diseases. Additionally, the detection of rib fractures nowadays is based on imaging techniques that, as experimental studies shows (Cattaneo et al., 2006), do not detect all the rib fractures. Thus, paleopathologists need to be very cautious when comparing the past prevalence of rib fractures with modern epidemiological data, since these are certainly underreported in the modern clinical practice (Marmor, 1969; Cattaneo et al., 2006).

Ribs fractures and causes of death

Pulmonary causes of death. One of the purposes of the present study was to explore if any association 
TABLE 7. Frequency of individuals with broken ribs by "artificial" groups of cause of death, number of ribs fractured and, healing status

\begin{tabular}{|c|c|c|c|c|c|c|c|c|c|c|c|c|c|c|c|c|}
\hline \multirow[b]{3}{*}{ Causes of death } & \multirow[b]{3}{*}{$N$} & \multirow[b]{3}{*}{$n$} & \multirow[b]{3}{*}{$\begin{array}{c}\% \\
(n / N)\end{array}$} & \multirow[b]{3}{*}{$\begin{array}{c}\% \\
(n / 47)\end{array}$} & \multicolumn{6}{|c|}{ Number of ribs fractured } & \multicolumn{6}{|c|}{ Healing status of rib fractures } \\
\hline & & & & & \multicolumn{3}{|c|}{ Single rib } & \multicolumn{3}{|c|}{ Two or more ribs } & \multicolumn{3}{|c|}{ Healing } & \multicolumn{3}{|c|}{ Healed } \\
\hline & & & & & $n$ & $\begin{array}{c}\% \\
(n / N) \\
\end{array}$ & $\begin{array}{c}\% \\
(n / 21) \\
\end{array}$ & $n$ & $\begin{array}{c}\% \\
(n / N) \\
\end{array}$ & $\begin{array}{c}\% \\
(n / 25) \\
\end{array}$ & $n$ & $\begin{array}{c}\% \\
(n / N) \\
\end{array}$ & $\begin{array}{c}\% \\
(n / 16) \\
\end{array}$ & $n$ & $\begin{array}{c}\% \\
(n / N) \\
\end{array}$ & $\begin{array}{c}\% \\
(n / 31) \\
\end{array}$ \\
\hline Pulmonary TB & 84 & 20 & 23.8 & 42.6 & 8 & 9.5 & 38.1 & 11 & 13.1 & 44.0 & 7 & 8.3 & 43.8 & 13 & 15.5 & 41.9 \\
\hline Pneumonia & 28 & 10 & 35.7 & 21.3 & 2 & 7.1 & 9.5 & 8 & 28.6 & 32.0 & 4 & 14.3 & 25.0 & 6 & 21.4 & 19.4 \\
\hline Other pulmonary diseases & 21 & 4 & 19.0 & 8.5 & 3 & 14.3 & 14.3 & 1 & 4.8 & 4.0 & 2 & 9.5 & 12.5 & 2 & 9.5 & 6.5 \\
\hline Total & 133 & 34 & 25.6 & 72.3 & 13 & 9.8 & 61.9 & 20 & 15.0 & 80.0 & 13 & 9.8 & 81.3 & 21 & 15.8 & 67.7 \\
\hline Nonpulmonary diseases & 64 & 13 & 20.3 & 27.7 & 8 & 12.5 & 38.1 & 5 & 7.8 & 20.0 & 3 & 4.7 & 18.7 & 10 & 15.6 & 32.3 \\
\hline Overall total & 197 & 47 & 23.9 & 100.0 & 21 & 10.7 & 100.0 & 25 & 12.7 & 100.0 & 16 & 8.1 & 100.0 & 31 & 15.7 & 100.0 \\
\hline
\end{tabular}

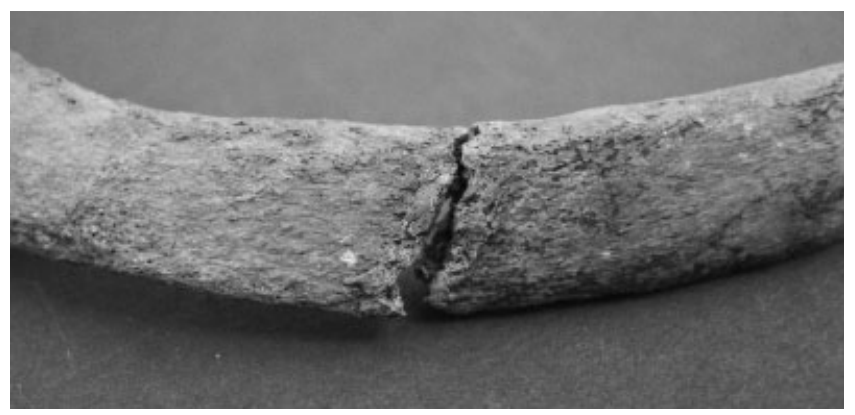

Fig. 5. Sixth left rib shaft fracture from the skeleton number 1139 (male, 70 years old, cause of death: pulmonary TB A16.2 group from ICD-10). Woven bone is present near the nonfused margins of the fracture line indicating an early and active process of healing.

existed between the prevalence of rib fractures and the respiratory diseases stated as the cause of death, such as pulmonary TB or pneumonia. At the beginning of the 20th century the statistics from 4,000 Portuguese tuberculous patients revealed that their mean life expectancy after the medical diagnosis of pulmonary TB was 2.5 years (Carvalho, 1907). This relatively long period of survival with the active infection would have been accompanied by severe and prolonged coughing, since this is the most common symptom of pulmonary TB (Hopewell, 1994). In modern medical practice there are reports of patients presenting rib stress fractures induced by coughing due to underlying respiratory diseases (Kawahara et al., 1997; Litch and Tuggy, 1998; Maeseneer et al., 2000; Hanak et al., 2005; Hillenbrand et al., 2006). The repeated loading of ribs by muscular contraction associated with coughing induces bone strain that can cause bone microdamage (Warden et al., 2002). With repetitive coughing this microdamage progressively accumulates until stress fractures occur (Brukner et al., 1999; Cullinane and Einhorn, 2002; Warden et al., 2002). Thus, rib stress fractures would be expected in some of the individuals studied in the present investigation since they lived in a period before the administration of antibiotics and when medical assistance was very rudimentary in Portugal (Ferreira, 1990). However, the results from the present study do not support this hypothesis. In fact, no significant differences in the prevalence of rib fractures were found between individuals who died from respiratory conditions (respectively those included in the A15-A19 and J00-J99 ICD-10 groups) and those who died from nonrespiratory conditions. This was further corroborated by a more fine grained analysis that considered prevalence in four cause-of-death groups (pulmonary TB; pneumonia; pulmonary diseases other than TB or pneumonia; and nonpulmonary diseases).

The findings presented are not surprising if compared with those reported for modern medical practice where rib cough-induced stress fractures are considered relatively uncommon (Connolly and Connolly, 2004), unless another pathological conditions, such as vitamin D deficiency (Brickley et al., 2007), are also present. However, this clinical assumption is not straightforward since it is possible that many of these fractures go unnoticed during routine radiological examinations (Schmidt, 1979; Warden et al., 2002). The majority of reports on rib stress fractures (Kawahara et al., 1997; Litch and Tuggy, 1998; Maeseneer et al., 2000; Warden et al., 2002; Hanak et al., 2005; Hillenbrand et al., 2006) results from their detection based on more sensitive and expensive imaging techniques such as, for example, scintighraphy (Maeseneer et al., 2004). Concerning rib stress fractures, as Warden et al. (2002, p 820) point out, "little is known regarding their etiology" and their occurrence is probably more easily explained by multifactorial aspects rather than by the isolated action of repetitive contraction of specific muscles. Additionally, compared to other types of fractures, stress fractures are generally incomplete and their remodeling is relatively rapid (Warden et al., 2002), making these more likely to go unnoticed in the context of skeletal remains analysis.

The evidence from the present study suggests that the etiology of rib fractures observed in the individuals who died from pulmonary TB is not easily ascribed to the muscular stress forces induced by coughing. One must emphasize, however, that the majority $(81.3 \%, n=13)$ of the 16 individuals presenting healing rib fractures (as opposed to healed rib fractures) died from pulmonary diseases (see Table 7). Nevertheless, concerning healing status no significant differences were found amongst the individuals who died from pulmonary conditions. This precludes inferences concerning a definitive relationship between healing rib stress fractures prevalence and pulmonary conditions. In specific cases this association cannot be definitively ruled out, such as in the individual number 1,139, who died from pulmonary TB, and whose 6 th left rib presented an incipient woven bony callus around the nonfused margins of the fracture line (see Fig. 5). Furthermore, this individual also presented additional remodeled fractures located on the right ribs, indicating that this individual also suffered traumatic events or earlier coughing injuries.

Although the hypothesis that rib stress fractures resulted from underlying respiratory pathologies such as 
TABLE 8. Rib fractures prevalence from archeological and identified skeletal series

\begin{tabular}{|c|c|c|c|c|c|}
\hline \multirow[b]{2}{*}{ Study reference } & \multirow[b]{2}{*}{ Skeletal series provenance } & \multirow{2}{*}{$\begin{array}{l}\text { Chronology } \\
\text { (centuries) }\end{array}$} & \multicolumn{3}{|c|}{$\begin{array}{l}\text { Number of individuals (with } \\
\text { ribs) }\end{array}$} \\
\hline & & & Observed & Fractured & $\%$ \\
\hline $\begin{array}{l}\text { Robledo and } \\
\text { Trancho (1999) }\end{array}$ & Xarea, Alméria, Spain & 9 th-15th & 142 & 15 & 10.6 \\
\hline Brickley (2006) & St. Martin's Church, Birmingham, UK & 18th-19th & 352 & 55 & 15.6 \\
\hline Assis (2007) & Constância, Portugal & 14th-19th & 36 & 6 & 16.7 \\
\hline Curate (2007) & Coimbra collection, Portugal & late 19 th-early 20 th & 97 & 5 & 5.2 \\
\hline Garcia (2007) & Leiria, Portugal & 12th-16th & 67 & 21 & 31.3 \\
\hline Jordana (2007) & Sant Pere Church, Terrasa, Barcelona, Spain & 4 th-13th & 53 & 7 & 13.2 \\
\hline Present study & Lisbon collection, Portugal & late 19th-first half 20 th & 197 & 47 & 23.9 \\
\hline
\end{tabular}

pulmonary TB, was difficult to support unequivocally, the inverse situation of pulmonary diseases (other than TB) resulting as an outcome of rib fractures was also investigated in the present study. The mean number of fractured ribs by individual in those who died from pneumonia was found to be higher than in the remaining groups of cause of death although the difference was not significant. These findings also reveal that in a time period before antibiotics and effective medical treatment most individuals presenting multiple number of rib fractures died from pulmonary diseases, namely pneumonia. Three out of four individuals with eight fractured ribs (the highest value recorded) died from bronchopneumonia. Of these, individual 270 had also rib fractures with signs of early healing indicating a recent traumatic event. A straightforward association between healing rib fractures resulting from thoracic injury events and pneumonia is difficult to prove. In fact, the evidence from the present study shows that most of the rib fractures presented by the individuals who died from pneumonia were healed (see Table 7). However, the presence of healing rib fractures and adjacent broken ribs on the same individual was found to be more common in those who died from pneumonia than in the remaining cause-ofdeath groups (see Table 5). It must be noted that this association is virtually impossible to predict in the context of human skeletal remains analyses.

Nowadays, the presence of multiple rib fractures in an individual is considered a sign of major injury (Bulger et al., 2000). According to Bulger and coauthors (2000), when the kinetic energy is sufficient to fracture more than five ribs, the injury will extend to the interior of the chest wall damaging the underlying intrathoracic soft tissues and causing death in most cases. Concerning the interplay between broken ribs and pneumonia, the evidence from the present study is in accordance with the modern epidemiological data, which shows an increasing incidence of pneumonia and associated mortality with higher number of ribs fractured (Holcomb et al., 2003; Sirmali et al., 2003; Flagel et al., 2005; Brasel et al., 2006). Bulger and coauthors (2000) noted that for each additional rib fracture in the elderly the mortality increased by $19 \%$ and the risk of pneumonia by $27 \%$.

Broken ribs are frequently caused by chest trauma and intrathoracic complications such as pneumothorax, hemothorax, lung contusion and laceration, aortic or vessel injury (Guttentag and Salwen, 1999) and even heart laceration (DiMaio and DiMaio, 2001) may occur. Furthermore, individuals with broken ribs from clinical contexts are at greater risk of developing pulmonary infection, especially pneumonia (Ziegler and Agarwal, 1994; Bulger et al., 2000; Holcomb et al., 2003; Sirmali et al.,
2003; Flagel et al., 2005). The rates of pulmonary complications after rib fractures secondary to trauma differs according to the different clinical contexts, varying between 35\% (Ziegler and Agarwal, 1994; Holcomb et al., 2003) and $48 \%$ (Flagel et al., 2005). The proportion of individuals who develop pneumonia in these circumstances may vary between $8.7 \%$ (Holcomb et al., 2003) and 27\% (Bulger et al., 2000). Also, mortality rates associated to rib fractures can be as high as $12 \%$ (Ziegler and Agarwal, 1994). Despite the modern clinical evidence, the establishment of a clear association between rib fractures and a respiratory cause of death based exclusively on macroscopical analysis is almost unreachable in anthropological contexts. Moreover, it must be acknowledged that the selection process for assembling the study sample described here could have biased results in terms of rib fracture prevalence and patterns, since it is not intentionally a random sample of the "Lisboa collection".

Nonpulmonary causes of death. Considering the remaining groups of cause-of-death classified under the ICD-10 codification system, the individuals who died from malignant diseases (Neoplasms group-C00-D48) were the most affected by rib fractures (42.9\%). The trunk is a common location of skeletal metastasis (Campanacci, 1999; Ortner, 2003; Bussard et al., 2008) mainly due to the high vascularization of the rib trabecular bone, a crucial factor for the colonization and growth of metastatic cancer cells (Bussard et al., 2008). The three individuals affected by rib fractures from this group of cause of death died respectively from larynx, uterus and breast cancer, and these last two types of cancer are, in fact, considered a common cause of skeletal metastasis according to Campanacci (1999). When rib metastasis occurs, the areas nearby the foci are more likely to undergo pathological fractures (Ortner, 2003). This type of fracture takes place when the structural integrity of the bone is compromised by some kind of underlying pathological processes such as neoplasms (Aufderheide and Rodríguez-Martín, 1998; Fayad et al., 2005). In the present study none of the individuals affected by rib fractures and with a cancer-related cause-of-death presented destructive or proliferative foci (except the typical healing callus of the fracture) near the line of breakage of the fractured ribs. Although the pathological nature of these rib fractures cannot be ruled out, other etiologies, such as blunt trauma, cannot be excluded. More systematic work on the association between rib fractures and tumour-related cause of death on identified skeletal collections is needed.

In the present study the six individuals presenting injury related causes of death, and classified under the 
ICD-10 group Injury, poisoning and other consequences of external causes group (S00-T98), did not reveal any evidence of rib fractures. These findings are not surprising since none of these individuals presented thoracic injury related to the cause of death, except the skeleton number 506. This specimen belonged to a 30-year-old military man who died in 1934, at the Military Hospital at Lisbon from injuries to the thorax, namely a "heart injury caused by a firearm" (Ferida do coração por arma de fogo). Broken costal elements would be expected, although no fractures were observed. This absence of injury signs on ribs is probably explained by anthropic reasons since the first to seventh ribs showed bilateral cut signs on their sternal extremities, most probably resulting from an autopsy (see Fig. 2).

For the remaining individuals studied, namely those simultaneously presenting rib fractures and a noninjury related cause of death, it is difficult to establish a direct association between broken ribs and violent injuries to the chest. However, in specific cases, a major external traumatic event can be evoked, such as in the four individuals (sks. 70, 119, 257, 270) presenting adjacent broken ribs bilaterally, two of them (sks. 119, 257) showing multiple fractures on the same rib. Adjacent broken ribs, each of these presenting multiple fractures, commonly result in a flail chest (DiMaio and DiMaio, 2001). In this situation, as pointed out by Guttentag and Salwen (1999, p 1130), "a segment of the chest wall can move paradoxically with respiration," and major pulmonary complications, or even death, may occur. In modern clinical contexts flail chest following chest injury due to blunt trauma is associated with a considerable mortality rate, such as for example in $17 \%$ of the patients reported by Liman et al. (2003).

Based on modern medical reports and taking into consideration the general pattern of rib fractures observed for the present study it can be suggested that many of the individuals with broken ribs probably suffered a violent (direct or indirect) force inflicted externally to the thorax. In fact, according to the clinical literature the majority of rib fractures are caused by external violence (Stimson, 1910), either through direct or indirect blunt chest trauma (Guttentag and Salwen, 1999; DiMaio and DiMaio, 2001; Liman et al., 2003). However, the present study shows that, even when the causes of death of the individuals under study are available, to establish a direct association between rib fracture patterns and their etiology is a difficult task, specially when the analyses of the remaining skeletal elements is not considered. The majority of "principles" stated in the anthropological and medical literature in order to infer the mechanisms of chest injury based on rib fractures analysis (Marmor, 1969; Schmidt, 1979; Lovell, 1997; DiMaio and DiMaio, 2001) are, with few exceptions (e.g. Love and Symes, 2004), more theoretical approaches than empirical ones. This implies that much more investigation is necessary on this important topic of human skeletal remains analysis. Two examples of this ambiguity are as follows. Posterior rib fractures are considered highly specific for direct violence, especially when occurring in abused children (Kleinman and Schlesinger, 1997; Lonergan et al., 2003), or as an indicator of indirect violent forces from behind towards the front or from the lateral sides of the chest (DiMaio and DiMaio, 2001). However, these fractures may also result as an outcome of repetitive muscular contraction, such as reported for rowers (Warden et al., 2002). Another example relies on the fractures of the first and second ribs, usually considered in the modern clinical practice as indicating severe blunt trauma to the thorax (Richardson et al., 1975; Woodring et al., 1982; Guttentag and Salwen, 1999; Resnick and Goergen, 2005). However, they have also been reported as occurring after a violent muscular pull (Waxman and Geshelin, 1947; Matsumoto et al., 2003). Thus, when transposing this evidence to the context of anthropological rib analysis, it is important to realize that distinguishing between rib fractures provoked by inflicted trauma, underlying pathology or muscle contraction, amongst other etiologies, may be challenging and needs further research. Such research will certainly improve the inferences that can be made from rib fractures analysis in archaeological and forensic context.

\section{CONCLUSION}

The analysis of rib fractures derived from skeletal material, both from archeological and forensic contexts, is a neglected topic in anthropological studies. Although these are accepted as being very common, their potential as an important source of biological and sociocultural inferences is underestimated. Moreover, comparisons among studies concerning rib fractures prevalence are virtually impossible since they are rarely reported in detail. The present study, performed on a sample of 197 individuals from the "Lisboa collection," revealed a high crude prevalence rate $(23.9 \%)$ of rib fractures and, inversely, a low true prevalence rate $(2.9 \%)$ in comparison with those reported in the few similar paleopathological studies available. Males and individuals from older age classes were the most affected by rib fractures. However, the interpopulation comparisons are difficult, not only because different chronological, geographical, biological, and sociocultural contexts are represented, but especially because preservation and representativity of ribs in skeletal assemblages are not considered in the paleopathological literature. Thus, future studies dealing with ribs should include rib representativeness as this influences accurate estimation of prevalence. Moreover, modern epidemiological data concerning rib fractures are not the most appropriate source for purposes of comparison with the results obtained from archaeological analysis. In fact, different demographical and epidemiological scenarios are represented and, most importantly, the majority of paleopathological studies are performed on individuals who lived before effective therapeutics, massive vaccinations and organized medical care, factors that certainly had influence in the manifestation and progression of pathological conditions as well as on their associated morbidity and mortality. Besides, considering the lack of systematic information on broken ribs, detailed information concerning rib fracture patterns is reported in the present study. These data are available for future studies on this topic allowing comparative analysis.

The associations under scrutiny in the present work, namely the interplay between the prevalence of rib fractures and the causes of death related to diseases of the respiratory system, especially pulmonary TB and pneumonia, was not substantiated. Thus, although prolonged and repetitive coughing is reported in modern clinical contexts as a cause of rib stress fractures, the present study does not confirm a higher prevalence of these types of fractures in individuals suffering from pulmonary tuberculosis in a period when no effective treatment or massive vaccinations to this disease existed. 
However, a more in depth analysis of the individuals who died from pulmonary diseases revealed a higher mean number of fractures, although not statistically significant, of ribs fractured in those who died from pneumonia. The presence of adjacent broken ribs and healing fractures were also more common in this causeof-death group. This evidence is in accordance with the modern clinical evidence, where the higher number of ribs fractured is associated with increased rates of morbidity, mainly intrathoracic complications, and mortality due to pneumonia. Nevertheless, a straightforward relationship between pneumonia and rib fractures was not demonstrated in the present investigation and is virtually unreachable during the study of human skeletal assemblages.

Future work should extend the analysis of rib fractures to all the individuals from the "Lisboa collection," especially those presenting an injury-related cause of death (those classified under the S00-T98 group from ICD-10). Moreover, future paleopathological studies dedicated to fractures occurring on both ribs and in the remaining skeletal components are necessary in order to achieve the overall distribution of fractures along the skeleton. The full range of possible rib fractures etiologies, including not only pathological but also biomechanical approaches to the mechanisms underlying rib fractures, should be further investigated in paleopathological, forensic and experimental specimens. Such integrated studies will allow more reliable inferences from the ultimate causes and consequences of trauma related fractures.

\section{ACKNOWLEDGMENTS}

The author thank the Fundação para a Ciência e Tecnologia (FCT), the Museu Bocage (Museu Nacional de História Natural, Lisboa), the Clínica Universitária de Imagiologia dos Hospitais da Universidade de Coimbra, and the Departamento de Antropologia at the Universidade de Coimbra. A special thanks goes to Ana Luísa Santos, Carina Marques, César Marques, Vasco Góis, and to the anonymous reviewers and editors. Thanks also to Cláudia Umbelino, Eugénia Cunha, João Pinheiro, and Sandra Assis. This investigation was presented at the 16th European Meeting of the Paleopathology Association, Santorini, Greece, in August 2006 (with support from the Institute of Bioarchaeology, Fundação para a Ciência e Tecnologia, and Centro de Investigação em Antropologia e Saúde) and at the IX Congreso Nacional de Paleopatología, Morella, Spain, in September 2007.

\section{LITERATURE CITED}

Agarwal SC, Dumitriu M, Tomlinson GA, Grynpas MD. 2004. Medieval trabecular bone architecture: the influence of age, sex, and lifestyle. Am J Phys Anthropol 124:33-44.

Aiello L, Dean C. 1990. An introduction to human evolutionary anatomy. London: Academic Press.

Assis S. 2007. A memória dos rios no quotidiano dos homens: contributo de uma série osteológica proveniente de Constância para o conhecimento dos padrões ocupacionais [Tese de Mestrado em Evolução Humana]. Coimbra: Departamento de Antropologia, Universidade de Coimbra.

Aufderheide A, Rodríguez-Martín C. 1998. The Cambridge encyclopedia of human paleopathology. Cambridge: Cambridge University Press.
Bass W. 1997. Human osteology: a laboratory and field manual. Columbia: Missouri Archaeological Society.

Bello SM, Thomann A, Dutour MSO, Andrews P. 2006. Age and sex bias in the reconstruction of past population structures. Am J Phys Anthropol 129:24-38.

Botella M, Alemán I, Jiménez S. 2000. Los huesos humanos: manipulación y alteraciones. Barcelona: Bellaterra.

Brasel KJ, Guse CE, Layde P, Weigelt JA. 2006. Rib fractures: relationship with pneumonia and mortality. Crit Care Med 34:1642-1646.

Brickley M. 2002. An investigation of historical and archaeological evidence for age-related bone loss and osteoporosis. Int $\mathrm{J}$ Osteoarchaeol 12:364-371.

Brickley M. 2006. Rib fractures in the archaeological record: a useful source of sociocultural information? Int J Osteoarchaeol 16:61-75.

Brickley M, Mays S, Ives R. 2007. An investigation of skeletal indicators of vitamin D deficiency in adults: effective markers for interpreting past living conditions and pollution levels in 18th and 19th century Birmingham, England. Am J Phys Antropol 132:67-79.

Brukner P, Bennell K, Matheson G. 1999. Stress fractures. Melbourne: Blackwell.

Buikstra J, Ubelaker D. 1994. Standards for data collection from human skeletal remains. Proceedings of a seminar at the Field Museum of Natural History. Fayetteville, Arkansas: Arkansas Archeological Survey Research Series; 44.

Bulger EM, Arneson MA, Mock CN, Jurkovich GJ. 2000. Rib fractures in the elderly. J Trauma 48:1040-1046; discussion1046-1047.

Bussard KM, Gay CV, Mastro AM. 2008. The bone microenvironment in metastasis: what is special about bone? Cancer Metastasis Rev 27:41-55.

Byers S, Roberts C. 2003. Bayes' theorem in paleopathological diagnosis. Am J Phys Antropol 121:1-9.

Campanacci M. 1999. Bone and soft tissue tumours: clinical features, imaging, pathology and treatment, 2nd ed. Padova and New York: Piccin Nuova Libraria and Springer-Verlag.

Campillo D. 2001. Introducción a la paleopatología. Barcelona: Bellaterra.

Cardoso HFV. 2005. Patterns of growth and development of the human skeleton and dentition in relation to environmental quality: a biocultural analysis of a 20th century sample of Portuguese documented subadult skeletons. Ph.D. thesis. Hamilton, Ontario: McMaster University.

Cardoso HFV. 2006. Brief communication: the collection of identified human skeletons housed at the Bocage Museum (National Museum of Natural History). Lisbon, Portugal. Am J Phys Anthropol 129:173-176.

Carvalho AS. 1907. I—quantos tuberculosos há no país?; II—o erythema nodoso é uma tuberculide; Assumptos dignos de estudo para os futuros congressos. IV Congresso da Liga Nacional contra a Tuberculose. Lisboa: Centro Typographico Colonial.

Cattaneo C, Marinelli E, Di Giancamillo A, Di Giancamillo M, Travetti O, Vigano L, Poppa P, Porta D, Gentilomo A, Grandi M. 2006. Sensitivity of autopsy and radiological examination in detecting bone fractures in an animal model: implications for the assessment of fatal child physical abuse. Forensic Sci Int 164:131-137.

Center for Disease Control. 2005. Epi Info $^{\text {TM }}$. Version 3.3.2. Release date: February 9, 2005. Atlanta: Centers for Disease Control and Prevention.

Cho H, Stout SD, Bishop TA. 2006. Cortical bone remodeling rates in a sample of African American and European American descent groups from the American Midwest: comparisons of age and sex in ribs. Am J Phys Anthropol 130:214-226.

Connolly LP, Connolly SA. 2004. Rib stress fractures. Clin Nucl Med 29:614-616.

Cullinane DM, Einhorn TA. 2002. Biomechanics of bone. In: Bilezikian JP, Raisz LG, Rodan GA, editors. Principles of bone biology, 2nd ed. New York: Academic Press. p 17-32.

Cunha E. 2006. Pathology as a factor of personal identity in forensic anthropology. In: Schmitt A, Cunha E, Pinheiro J, edi- 
tors. Forensic anthropology and medicine: complementary sciences from recovery to cause of death. Totowa, NJ: Humana Press. p 333-358.

Cunha E, Pinheiro J. 2005, 2006. A linguagem das fracturas, a perspectiva da antropologia forense. Antrop Port 22-23:223-243.

Curate F. 2007. Fracturas de las costillas en la Colección de Esqueletos Identificados del Museo Antropológico de la Universidad de Coimbra. Poster apresentado ao IX Congreso Nacional de Paleopatología, Morella (Els Ports, Castelló), España, 26-29 Septembre de 2007.

DiMaio VJ, DiMaio D. 2001. Forensic pathology, 2nd ed. Boca Raton: CRC Press.

Dudar JC. 1993. Identification of rib number and assessment of intercostal variation at the sternal rib end. J Forensic Sci 38:788-797.

Fayad LM, Kamel IR, Kawamoto S, Bluemke DA, Frassica FJ, Fishman EK. 2005. Distinguishing stress fractures from pathologic fractures: a multimodality approach. Skeletal Radiol 34:245-259.

Ferreira FG. 1990. História da saúde e dos serviços de saúde em Portugal. Lisboa: Fundação Calouste Gulbenkian.

Fily ML, Crubézy E, Ludes B, Rougé D, Midant-Reynes B. 2001. Sternal perforation and bifid ribs: a possible familial case 5400 years old. An example of epigenetic control of development? Bull Mém Soc Anthropol Paris 13:5-13.

Flagel BT, Luchette FA, Reed RL, Esposito TJ, Davis KA, Santaniello JM, Gamelli RL. 2005. Half-a-dozen ribs: the breakpoint for mortality. Surgery 138:717-725.

Franciscus R, Churchill S. 2002. The costal skeleton of Shanidar 3 and a reappraisal of Neandertal thoracic morphology. J Hum Evol 42:303-356.

Frost HM. 2003. On changing views about age-related bone loss. In: Agarwal CN, Stout SD, editors. Bone loss and osteoporosis: an anthropological perspective. New York: Kluwer Academic. p 19-31.

Garcia S. 2007. Maleitas do corpo em tempos medievais: indicadores paleodemográficos, de stresse e paleopatológicos numa série osteológica urbana de Leiria [Tese de Doutoramento em Antropologia Biológica]. Coimbra: Universidade de Coimbra.

Glencross B, Sawchuk L. 2003. The person-years construct: ageing and the prevalence of health related phenomena from skeletal samples. Int J Osteoarchaeol 13:369-374.

González-Reimers E, García-Valdecasas-Campelo E, SantolariaFernández F, Milena-Abril A, Rodríguez-Rodríguez E, Martínez-Riera A, Pérez-Ramírez A, Alemán-Valls MR. 2005. Rib fractures in chronic alcoholic men: relationship with feeding habits, social problems, malnutrition, bone alterations, and liver dysfunction. Alcohol 37:113-117.

Grauer AL, Roberts CA. 1996. Paleoepidemiology, healing, and possible treatment of trauma in the medieval cemetery population of St. Helen-on-the-walls, York, England. Am J Phys Anthropol 100:531-544.

Gray H. 1995. Gray's anatomy. New York: Barnes and Noble.

Groves S, Roberts C, Johnstone C, Hall R, Dobney K. 2003. A high status burial from Ripon Cathedral. North Yorkshire, England: differential diagnosis of a chest deformity. Int J Osteoarchaeol 13:358-368.

Grynpas MD. 2003. The role of bone quality on bone loss and bone fragility. In: Agarwal CN, Stout SD, editors. Bone loss and osteoporosis: an anthropological perspective. New York: Kluwer Academic. p 33-44.

Guttentag AR, Salwen JK. 1999. Keep your eyes on the ribs: the spectrum of normal variants and diseases that involve ribs. Radiographics 19:1125-1142.

Hanak V, Hartman TE, Ryu JH. 2005. Cough-induced rib fractures. Mayo Clin Proc 80:879-882.

Henderson J. 1987. Factors determining the state of preservation of human remains. In: Boddington A, Garland A, Janaway $\mathrm{R}$, editors. Death, decay and reconstruction: approaches to archaeology and forensic science. Manchester: Manchester University Press. p 43-54.

Hillenbrand A, Henne-Bruns D, Wurl P. 2006. Cough induced rib fracture, rupture of the diaphragm and abdominal herniation. World J Emerg Surg 1:e34.
Holcomb JB, McMullin NR, Kozar RA, Lygas MH, Moore FA. 2003. Morbidity from rib fractures increases after age 45 . J Am Coll Surg 196:549-555.

Hopewell PC. 1994. Overview of clinical tuberculosis. In: Bloom BL, editor. Tuberculosis: pathogenesis, protection, and control. Washington DC: ASM Press. p 25-46.

Hoppa R, Saunders S. 1998. Two quantitative methods for rib seriation in human skeletal remains. J Forensic Sci 43:174-177.

Iwamoto J, Takeda T. 2003. Stress fractures in athletes: review of 196 cases. J Orthop Sci 8:273-278.

Jordana XC. 2007. Caracterització i evolució d'una comunitat medieval catalana: estudi bioantropològic de les inhumacions de les Esglésies de Sant Pere [Tesi Doctoral]. Barcelona: Universitat Autònoma de Barcelona.

Jurmain R. 1999. Stories from the skeleton: behavioural reconstruction in human osteology. London: Taylor \& Francis.

Kawahara H, Baba H, Wada M, Azuchi M, Ando M, Imura S. 1997. Multiple rib fractures associated with severe coughing-a case report. Int Orthop 21:279-281.

Kelley M, Micozzi M. 1984. Rib lesions in chronic pulmonary tuberculosis. Am J Phys Anthropol 65:381-386.

Kemp AM, Butler A, Morris S, Mann M, Kemp KW, Rolfe K, Sibert JR, Maguire S. 2006. Which radiological investigations should be performed to identify fractures in suspected child abuse? Clin Radiol 61:723-736.

Kleinman PK, Schlesinger AE. 1997. Mechanical factors associated with posterior rib fractures: laboratory and case studies. Pediatr Radiol 27:87-91.

Lambert PM. 2002. Rib lesions in a prehistoric Puebloan sample from Southwestern Colorado. Am J Phys Anthropol 117:281292.

Liman ST, Kuzucu A, Tastepe AI, Ulasan GN, Topcu S. 2003. Chest injury due to blunt trauma. Eur J Cardiothorac Surg 23:374-378.

Litch JA, Tuggy M. 1998. Cough induced stress fracture and arthropathy of the ribs at extreme altitude [abstract]. Int J Sports Med 19:220-222.

Lonergan GJ, Baker AM, Morey MK, Boos SC. 2003. From the archives of the AFIP: child abuse: radiologic-pathologic correlation. Radiographics 23:811-845.

Love JC, Symes SA. 2004. Understanding rib fracture patterns: incomplete and buckle fractures. J Forensic Sci 49:1153-1158.

Lovell NC. 1997. Trauma analysis in paleopathology. Yrbk Phys Anthropol 40:139-170.

Maeseneer M, Mey J, Debaere C, Meysman M, Osteaux M. 2000. Rib fractures induced by coughing: an unusual cause of acute chest pain. Am J Emerg Med 18:194-197.

Maeseneer MD, Mey JD, Lenchik L, Everaert H, Osteaux M. 2004. Helical CT of rib lesions: a pattern-based approach. Am J Roentgenol 182:173-179.

Mann R. 1993. A method for siding and sequencing human ribs. J Forensic Sci 38:151-155.

Marmor L. 1969. Fractures of the ribs and sternum. Trauma 10:69-88.

Matos V. 2003. Incursões no trilho da tuberculose pulmonar: diagnóstico diferencial com base no estudo da Colecção de Esqueletos Identificados do Museu Bocage, Lisboa [Tese de Mestrado em Evolução Humana]. Coimbra: Universidade de Coimbra.

Matos V, Santos AL. 2006. On the trail of pulmonary tuberculosis based on rib lesions: results from the Human Identified Skeletal Collection from the Museu Bocage (Lisbon. Portugal). Am J Phys Anthropol 130:190-200.

Matsumoto T, Fujita K, Fujioka H, Tsunoda M, Yoshiya S, Kurosaka M, Mizuno K. 2003. Stress fracture of the first rib in a soccer player: a rare etiology of shoulder pain. J Shoulder Elbow Surg 12:197-199.

Mays S, Fysh E, Taylor GM. 2002. Investigation of the link between visceral surface rib lesions and tuberculosis in a medieval skeletal series from England using ancient DNA. Am J Phys Anthropol 119:27-36.

Mays SA. 2006. Age-related cortical bone loss in women from a 3rd-4th century $\mathrm{AD}$ population from England. Am J Phys Anthropol 129:518-528. 
Molto JE. 1990. Differential diagnosis of rib lesions: a case study from middle Woodland Southern Ontario circa 230 A.D. Am J Phys Anthropol 83:439-447.

Moraitis K, Spiliopoulou C. 2006. Identification and differential diagnosis of perimortem blunt force trauma in tubular long bones. Forensic Sci Med Pathol 2:221-229.

Ortner D. 2003. Identification of pathological conditions in human skeletal remains, 2nd ed. New York: Academic Press.

Owers SK, Pastor RF. 2005. Analysis of quantitative methods for rib seriation using the Spitalfields documented skeletal collection. Am J Phys Anthropol 127:210-218.

Pfeiffer S. 1991. Rib lesions and New World tuberculosis. Int J Osteoarchaeol 1:191-198.

Prosser I, Maguire S, Harrison SK, Mann M, Sibert JR, Kemp AM, Welsh Child Protection Systematic Review Group. 2005. How old is this fracture? Radiologic dating of fractures in children: a systematic review. Am J Roentgenol 184:1282-1286.

Raff J, Cook DC, Kaestle F. 2006. Tuberculosis in the New World: a study of ribs from the Schild Mississippian population, West-central Illinois. Mem Inst Oswaldo Cruz, Rio de Janeiro 101:25-27.

Resnick D, Goergen T. 2005. Traumatic diseases: physical injury, concepts and terminology. In: Resnick D, Kransdorf M, editors. Bone and joint imaging, 3rd ed. Philadelphia: Elsevier Saunders. p 789-830.

Richardson JD, McElvein RB, Trinkle JK. 1975. First rib fracture: a hallmark of severe trauma. Ann Surg 181:251-254.

Roberts CA, Boylston A, Buckley L, Chamberlain AC, Murphy EM. 1998. Rib lesions and tuberculosis: the paleopathological evidence. Tuberc Lung Dis 79:55-60.

Roberts CA, Connell B. 2004. Guidance on recording palaeopathology. In: Brickley M, McKinley J, editors. Guidance to standards for recording human skeletal remains. SouthamptonReading: Institute of Field Archaeologists and British Association of Biological Anthropology and Osteoarchaeology. p 34-39.

Roberts CA, Cox M. 2003. Health and disease in Britain: from prehistory to the present day. Phoenix Mill, Thrupp, Stroud, Gloucestershire: Sutton Publishing.

Roberts CA, Lucy D, Manchester K. 1994. Inflammatory lesions of ribs: an analysis of the terry collection. Am J Phys Anthropol 95:169-182.

Roberts CA, Manchester K. 2005. The archaeology of disease, 3rd ed. London: Sutton Publishing.

Robledo B, Trancho GJ. 1999. Fracturas craneales y postcraneales en la población hispanomusulmana de Xarea (Vélez Rubio, Almeria). In: Sanchéz JAS, editor. Actas del V Congreso Nacional de Paleopatología: sistematización metodológica en Paleopatología (Alcalá la Real, 9 Abril-2 Mayo de 1999). Alcalá la Real: Asociación Española de Paleopatología y Ayuntamiento de Alcalá la Real. p 182-189.

Rodríguez-Martín C. 2006. Identification and differential diagnosis of traumatic lesions of the skeleton. In: Schmitt A, Cunha E, Pinheiro J, editors. Forensic anthropology and medicine: complementary sciences from recovery to cause of death. Totowa, NJ: Humana Press. p 197-221.

Santos AL. 2000. A skeletal picture of tuberculosis: macroscopic, radiological, biomolecular, and historical evidence from the Coimbra identified skeletal collection. Ph.D. thesis. Coimbra: University de Coimbra.

Santos AL, Roberts C. 2001. A picture of tuberculosis in young Portuguese people in the early 20th century: a multidisciplinary study of the skeletal and historical evidence. Am J Phys Anthropol 115:38-49.

Santos AL, Roberts CA. 2006. Anatomy of a serial killer: differential diagnosis of tuberculosis based on rib lesions of adult individuals from the Coimbra identified skeletal collection. Portugal. Am J Phys Anthropol 130:38-49.
Sauer NJ. 1998. The timing of injuries and manner of death: distinguishing among antemortem, perimortem and postmortem trauma. In: Reiches KJ, editor. Forensic osteology: advances in the identification of human remains, 2nd ed. Springfield: Charles C. Thomas. p 321-332.

Schmidt G. 1979. Rib-cage injuries indicating the direction and strength of impact. Forensic Sci Int 13:103-110.

Seeman E, Delmas PD. 2006. Bone quality-the material and structural basis of bone strength and fragility. N Engl J Med 354:2250-2261.

Sievänen H, Kannus P, Järvinen TL. 2007. Bone quality: an empty term. PLoS Med 4:e27.

Simmons T, Haglund WD. 2005. Anthropology in a forensic context. In: Hunter J, Cox M, editor. Forensic archaeology: advances in theory and practice. London: Routledge. p 159176.

Sirmali M, Türüt H, Topçu S, Gülhan E, Yazici Ü, Kaya S, Tastepe I. 2003. A comprehensive analysis of traumatic rib fractures: morbidity, mortality and management. Eur J Cardiothorac Surg 24:133-138.

Sledzik PS. 1998. Forensic taphonomy: postmortem decomposition and decay. In: Reiches KJ, editor. Forensic osteology: advances in the identification of human remains. Springfiled: Charles C. Thomas. p 109-119.

SPSS. 2005. SPSS for Windows. Release 14.0.0. Chicago: SPSS, Inc.

Stimson LA. 1910. A practical treatise on fractures and dislocations, 6th ed. New York: Lea \& Febiger.

Streeter M, Stout SD. 2003. The histomorphometry of the subadult rib: age-associated changes in bone mass and the creation of peak bone mass. In: Agarwal CN, Stout SD, editors. Bone loss and osteoporosis: an anthropological perspective. New York: Kluwer Academic. p 91-101.

Usher BM, Christensen MN. 2000. A sequential developmental field defect of the vertebrae, ribs, and sternum, in a young woman of the 12th century AD. Am J Phys Anthropol 111: 355-367.

Victorino GP, Chong TJ, Pal JD. 2003. Trauma in the elderly patient. Arch Surg 138:1093-1098.

Wakely J, Manchester K, Roberts C. 1991. Scanning electron microscopy of rib lesions. Int J Osteoarchaeol 1:185-189.

Waldron T. 1987. The relative survival of the human skeleton: implications for paleopathology. In: Boddington A, Garland R, Janaway R, editors. Death, decay and reconstruction. Manchester: Manchester University Press. p 55-64.

Waldron T. 2007. Palaeoepidemiology: the measure of disease in the human past. Walnut Creek, CA: Left Coast Press.

Walker PL. 2001. A bioarchaeological perspective on the history of violence. Ann Rev Anthropol 30:573-596.

Warden SJ, Gutschlag FR, Wajswelner H, Crossley KM. 2002. Aetiology of rib stress fractures in rowers. Sports Med 32: 819-836.

Waxman A, Geshelin H. 1947. Spontaneous fracture of the first rib due to muscle pull: a case report. Calif Med 67:243-244.

White T. 2000. Human osteology, 2nd ed. San Diego: Academic Press.

Woodring JH, Fried AM, Hatfield DR, Stevens RK, Todd EP. 1982. Fractures of first and second ribs: predictive value for arterial and bronchial injury. Am J Roentgenol 138:211-215.

World Health Organization. 2006. International statistical classification of diseases and related health problems. 10th Revision, version for 2006. Processed on 05-04-2006. Accessed in 28-6-2006. Geneve: available online at http://www3.who.int/ icd/currentversion/fr-icd.htm.

Ziegler DW, Agarwal NN. 1994. The morbidity and mortality of rib fractures. J Trauma 37:975-979. 